\title{
El teatro de Elías Castelnuovo (1926-1934): humor tragicómico, vanguardia y política revolucionaria
}

\author{
Esteban Da Ré \\ Instituto de Filología y Literaturas Hispánicas "Dr. Amado Alonso" - Universidad de Buenos Aires \\ estebanvd@gmail.com \\ ORCID: 0000-0001-7809-2847
}

Title: Elias Castelnuovo's Theater (1926-1934): Tragicomic Humor, Avant-garde and Revolutionary Politics

Resumen: Entre los años 1926 y 1934, Elias Castelnuovo estrena seis obras de teatro vinculadas con distintos proyectos colectivos, que se configuran como los iniciadores del teatro "independiente" argentino: Teatro Libre (1927), Teatro Experimental del Arte (1928) y Teatro Proletario (1934). La hipótesis de que estas obras teatrales se proponen criticar la cultura y la sociedad dominantes, al igual que su producción narrativa anterior, a partir de la apelación a un tono tragicómico y de la apropiación de rasgos vanguardistas permite reconsiderar su recepción mayoritaria y advertir la singularidad del entramado entre estética y politica de su apuesta literaria.

Palabras clave: Elías Castenuovo - literatura argentina - teatro - humor - política revolucionaria

Abstract: Between 1926 and 1934, Elias Castelnuovo performed for the first time six theater plays, related with different collective projects, that were the founders of the Argentinian "independent" theater: Teatro Libre (1927), Teatro Experimental de Arte (1928) and Teatro Proletario (1934). This article's hypothesis is that these plays meant to criticize the dominant culture and society

DOI: https://doi.org/10.46688/ahmoi.n20.346

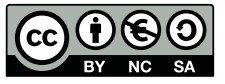

Obra bajo licencia Creative Commons 4.0 International (Atribución - NoComercial - Compartirlgual) 
using a tragicomic tone and the appropriation of avant-garde features, as in his previous prose fiction. This allows us to reconsider the way in which his work was mainly received, and observe the singularity of Castelnuovo's grip between aesthetics and politics.

Keywords: Elias Castelnuovo - Argentine literature - theater - humor - revolutionary politics

Recepción: 24 de septiembre de 2021. Aceptación: 10 de enero de 2022.

$* * *$

La obra de Elías Castelnuovo, dado el impacto que tuvo en su época y la importancia de los proyectos artísticos y culturales de los que participó el autor, configura un momento insoslayable de la renovación que se opera en la literatura y la cultura argentina durante las décadas del 20 y del 30. En especial, se muestra relevante para reflexionar en torno de las relaciones entre arte y politica, en un contexto signado por la modernización de Buenos Aires, la irrupción de las vanguardias históricas y la Revolución soviética. Castelnuovo nace en Montevideo el 6 de agosto de 1893 y fallece en Buenos Aires el 12 de octubre de 1982. Cuenta en sus Memorias (1974, p. 74) que decide viajar hacia esta ciudad a la edad de diecinueve años, atraído por sus lecturas del periódico anarquista La Protesta. En 1919 comienza a publicar artículos y ficciones y, desde ese momento, se convierte en una figura clave de los principales proyectos politico-culturales de la izquierda y en un referente ineludible, ya sea por amor o por espanto, para las futuras generaciones de escritores. Si bien su trayectoria militante comienza en el anarquismo, durante la década del 30 se aproxima, no sin conflictos, al creciente Partido Comunista (PC) de la Argentina al igual que otros artistas e intelectuales, como su amigo Roberto Arlt. Durante los 40 y 50 también participa de publicaciones peronistas, pero sin abandonar, en ambos casos, sus principios politicos anarquistas y su mirada crítica sobre estas experiencias politicas. Consultado más adelante sobre las derivas de su militancia, Castelnuovo responde: "Prefiero estar equivocado con las masas y no estar solo con la verdad en contra de las masas" (Castelnuovo, 2020).

Pese a la relevancia que tuvo en su contexto, la mayor parte de los críticos que se dedicaron al estudio de su obra sostiene que su producción se singulariza por sus desaciertos y la consideran "tremendista", "esquemática", de "mal gusto". En este sentido, se sostiene que su proyecto literario se malogra en tanto su poética conservadora, que abrevaría del realismo y del naturalismo decimonónicos, entraría en contradicción con su apuesta por la revolución política. No obstante, parte de la recepción que tuvieron las obras en su propia época advierte un tono humorístico 
en la literatura de Castelnuovo. Este humor, entramado con la tragedia y con una apuesta por la sensibilidad expresionista, permite realizar otro abordaje de su obra y advertir que sus exageraciones tienen un objetivo paródico y satírico para la crítica de los discursos literarios y sociales dominantes de su época: la novela sentimental, el catolicismo, el naturalismo, el positivismo, el determinismo biológico, entre otros.

$\mathrm{El}$ abierto tono tragicómico que se percibe en sus primeras publicaciones en la prensa anarquista entre 1919 y 1923 se mantiene constante, aunque más sutil y sofisticado, en sus textos posteriores. La persecución política que padece Castelnuovo en 1936, bajo el riesgo de ser expulsado del país por la Ley de Residencia, interrumpe su producción hasta la edición de Calvario, en 1949. Entre 1923 y 1936 Castelnuovo publica trece libros al tiempo que participa de una diversidad de proyectos culturales, artísticos y literarios, dentro de los que se destaca el llamado Grupo de Boedo, conjunto de escritores que se proponen contribuir, aún en su relativa diversidad ideológica, a la conformación de una cultura revolucionaria (Prieto, 1959).

La obra literaria de Elías Castelnuovo tiende a ser analizada bajo el desarrollo de este grupo entre 1924 y 1927 y, en consecuencia, se hace foco en su obra narrativa. No obstante, entre los años 1926 y 1934, Castelnuovo estrena y publica seis obras de teatro en el marco de distintas experiencias colectivas, que se configuran como los iniciadores del teatro "independiente" en la Argentina (Fukelman, 2017): Teatro Libre (1927), Teatro Experimental del Arte (1928) y Teatro Proletario (1934). Estas iniciativas se propusieron, al igual que el Grupo de Boedo, contribuir en la creación de una cultura revolucionaria.

Los contados trabajos que estudian esta producción teatral de Castelnuovo no consideraron el tono humorístico y, en consecuencia, aún con sus matices e inflexiones, llegan a conclusiones muy similares a las producidas por la crítica literaria predominante sobre sus cuentos. Por tal motivo, abordar el estudio de su dramaturgia bajo esta nueva perspectiva permite reconsiderar el estado de la cuestión y elaborar nuevas hipótesis sobre la poética de Castelnuovo.

\section{La recepción de la obra de Elías Castelnuovo por la crítica literaria}

Tinieblas (1923), primer libro de Elías Castelnuovo, es su obra más analizada, muy probablemente, debido a que en 1924 consigue el Premio Municipal y ese mismo año es reeditada como el libro inaugural de la colección "Los Nuevos" de la revista Los Pensadores, una de las principales publicaciones impulsadas por el Grupo de Boedo. A partir del análisis de esta obra, Adolfo Prieto y Juan Carlos Portantiero elaboran, en gran medida, las lecturas sobre la poética de Castelnuovo y sobre este 
grupo que son retomadas por estudios posteriores. Prieto señala que su literatura se caracteriza por la apelación a "la descripción objetiva (el retrato que impugna por sí mismo)" (1959, p. 326) así como a "la mera piedad mezclada en un principio con arrebatos de impotente rebeldia" (p. 326). Por su parte, Juan Carlos Portantiero afirma que las ficciones de Castelnuovo se caracterizan por entramar elementos del "populismo" y del "naturalismo", y por un "fatidismo mesiánico" (1961, p. 120) que tiene como fin provocar una "visión piadosa de la clase trabajadora" (p. 120). Bajo este marco, Carlos Giordano señala los "desbordes" de su poética, por ingenua, tremendista y esquemática (1980, p. 42); Eduardo Romano (1981) y Beatriz Sarlo (1988) destacan su exageración de los recursos naturalistas y de su apelación al horror; Adriana Astutti afirma que el realismo de Castelnuovo es "involuntariamente caricaturesco" (2002, p. 428); Sylvia Saitta encuentra que el autor reprodujo pero, a su vez, "excedió" (2008, p. 100) los presupuestos de Boedo tanto por su lógica religiosa como por su fascinación por lo monstruoso; y, por último, Marcela Croce encuentra que en su obra la "alternativa revolucionaria resulta sepultada” (2017, p. 201) por su perspectiva determinista biológica, evangélica y pietista.

En paralelo, existe una serie de estudios críticos que ofrecen una mirada diferente a la dominante. Por ejemplo, Nicolás Rosa califica a Castelnuovo como "bricoleur de los restos de las Enciclopedias Populares" (1997, p. 113); Leonardo Candiano y Lucas Peralta destacan que sus ficciones persiguen motivar la acción de quienes leen (2007, p. 209); Oscar Blanco sostiene que la literatura de Boedo continúa pero critica a la novela positivista, por señalar que la miseria moral es consecuencia de la miseria material (2012, p. 16); asi como Gabriela García Cedro afirma que Boedo se inscribe dentro de las vanguardias porteñas por su experimentación, rechazo de modelos previos y su cuestionamiento a las instituciones (2013, pp. 376-378).

Pese a que la mayor parte de análisis que han abordado la obra de Castelnuovo señalan un tono serio y trágico en sus ficciones, existen otros que advierten un tono humorístico y paródico, pero como un rasgo excepcional dentro de su literatura. En efecto, Francine Masiello señala que Castelnuovo parodia al naturalismo pero que, no obstante, no logra escapar por completo de su ideología (1986, pp. 197-200). John Eipper advierte que la condición de "humorista" (1995, p. 31) de Castelnuovo es una "faceta olvidada", aunque afirma que este tono humorístico es una contingencia que acontece solo en el comienzo de su producción. Por su parte, Adriana Rodríguez Pérsico percibe su tono burlesco sobre el discurso médico, pero encuentra una "contradicción" (2013, p. 34) en Castelnuovo, en tanto esta parodia coexiste en su poética con un "naturalismo de trazos gruesos". 
El humor en la poética de Castelnuovo, asimismo, es percibido por parte de su primera recepción. En este sentido, la breve biografia de Castelnuovo que acompaña la publicación de Notas de un literato naturalista, conjunto de relatos que aparecen en 1923 -mismo año de la aparición de Tinieblas-, hace énfasis en su "humorismo filosófico" (1923, $\mathrm{s} / \mathrm{n}$ ) sobre "las costumbres, las ideas y las imbecilidades" de su tiempo, así como señala que en sus "burlas llenas de causticidad [...] hay, sin embargo, [...] un timbre patético de tristeza".

El análisis de las obras de teatro de Elías Castelnuovo tuvo un desarrollo mucho menor que su narrativa y se mantiene dentro de las lineas interpretativas predominantes. Así, Beatriz Sarlo sostiene que con la publicación de Vidas proletarias (1934) Castelnuovo cambia de "pacto y de perspectiva de representación" (Sarlo, 1988, p. 202) al poner el foco en "cuestiones obreras" (p. 202), si bien muchos de los rasgos de su primer libro, según la autora, "siguen siendo para siempre sus obsesiones literarias" (p. 203). No obstante, Sarlo pasa por alto la producción teatral de Castelnuovo entre 1926 y 1934 y su participación en distintos colectivos artísticos. Asimismo, continúa sin advertir su tono humorístico y señala que en su teatro prevalece "la violencia y la derrota" (p. 204) y que sus obras continúan cargando "con la determinación de la herencia cultural y biológica" (p. 204). Por su parte, Sylvia Saitta también limita el estudio de la dramaturgia de Elias Castelnuovo al análisis de Vidas proletarias y sostiene que estas obras teatrales de Castelnuovo constituyen una "puesta en ficción de las consignas del Partido Comunista" (Saitta, 2008, 194). Respecto de la experiencia en general de Teatro Proletario, María Fukelman encuentra que su propósito "era incentivar, desde el teatro, la lucha de clases para contribuir a la revolución socialista" (2017, p. 117) al tiempo que Magalí Devés afirma que aún en la cercanía a la órbita comunista, la experiencia del Teatro Proletario no puede interpretarse como un mero reflejo de la política partidaria del PC (2020, p. 180).

\section{Castelnuovo, crítica teatral y humor: revista Prometeo (1919)}

Ya en sus primeras colaboraciones periodísticas, Castelnuovo manifiesta su interés por el teatro y publica en 1919 dos artículos en Prometeo, revista de la tendencia anarcobolchevique, en los que aborda estas problemáticas. $\mathrm{El}$ anarcobolchevismo se diferenciaba de otras corrientes dentro del anarquismo por apoyar a la revolución soviética, en lugar de ser refractaria, aunque, al mismo tiempo, intentaba hacerlo "sin subordinarse a la hegemonía de su política” (Doeswijk, 2013, p. 286). En el número 4, publicado en la primera quincena del mes de octubre, Castelnuovo firma el artículo "Críticas teatrales: El sainete", en donde realiza 
una invectiva en contra de ese género, cargada de humor y sarcasmo y afirma, por ejemplo, que "Carlos María Pacheco evacúa uno [sainete] por semana" (Castelnuovo, 1919a: 13) y que "el buen gusto a fuerza de recibir [en el sainete] golpes y porrazos, se encuentra débil y atragantado" (p. 13). Respecto de las formas artísticas en particular, Castelnuovo realiza una crítica del tipo de humor que propone este género teatral, que consiste en el "chiste barato, ordinario [...] hecho a expensas del gringo que no habla bien el español" (p. 14). Como contrapartida, formula una defensa de otro tipo de humor, significativamente, el tipo de humor que Castelnuovo entrama en sus artículos periodísticos y que va a proponer en sus textos literarios posteriores: "El sarcasmo volteriano, la ironía aguda, la sátira, todo lo que hiere el corazón y la inteligencia” (p. 14). La ironía que defiende Castelnuovo coincide con la definición clásica del "empleo de una palabra con el sentido de su antónimo" (Ducrot y Todorov, 2005: 318), pero que, como se infiere en el adjetivo "aguda", no se detiene alli sino que, desde una perspectiva pragmática, persigue formular "un señalamiento evaluativo, casi siempre peyorativo" (Hutcheon, 1992, p. 177). En efecto, esta ironía presupone la elaboración de un pensamiento por parte del receptor, en contraposición al humor literal que Castelnuovo encuentra en el sainete, que subestima las capacidades de su público. En este sentido, en estos artículos se realiza una defensa de la sátira, dado que "tiene como finalidad corregir, ridiculizándolos, algunos vicios e ineptitudes del comportamiento humano" (Hutcheon, 1992, p. 178). La radicalidad de la crítica humorística hacia el sainete llega a su punto más alto en el cierre del artículo: "No sabemos quién dijo que para regenerar el teatro habia que colgar a todos los autores nacionales, y si no lo dijo nadie, lo decimos nosotros" (Castelnuovo, 1919a, p. 14).

En el número siguiente de la revista, publicado en la segunda quincena de octubre de 1919, Castelnuovo publica el artículo "Literatura proletaria" en el que, como correlato de su texto anterior, propone las características de una nueva literatura, que se oponga a la "aristocrática" (Castelnuovo, 1919b, p. 11) y que se configure como una "literatura racional, científica, anarquista" (p. 11). La "literatura proletaria", de esta manera, tiene un componente clasista determinante que se vincula con el racionalismo y la ciencia. Como señala Suriano, los anarquistas de finales del siglo XIX y principios del XX pusieron en marcha un proyecto cultural alternativo de carácter integral, cuyo objetivo era impartir una nueva educación a los trabajadores y construir una nueva identidad con un contenido iluminista y racional, basado en una fuerte impugnación de la sociedad capitalista (2001, p. 217-248). De manera coherente con el proyecto político del que participa, Castelnuovo sostiene en el artículo que "el teatro como la escuela, son lacayos de la burguesía, órganos 
de poder, instrumentos de opresión y embrutecimiento" (1919b, p. 11). Asimismo, encuentra que casi todas las obras están construidas sobre "la propiedad privada, el amor legislado, la familia y el honor [...], el antiguo y nuevo testamento" (11). Estos cuestionamientos ideológicos preanuncian las críticas a los discursos dominantes de su época que Castelnuovo formulará en su obra posterior: el amor romántico, la familia y la religión como soportes ideológicos necesarios, en el ámbito privado, para la reproducción del capitalismo imperante.

Para articular estos cuestionamientos, el humor tragicómico se esgrime como su arma fundamental. Como señala Henri Bergson, la risa irrumpe cuando se ponen en evidencia aspectos de las personas y de la sociedad que, por "su rigidez y mecanicidad, las hace asemejarse a una cosa” (2009, p. 68). Para tal fin, sostiene Bergson que los recursos humorísticos se valen principalmente de tres procedimientos: la repetición de una situación, movimiento o rasgo; la inversión de las expectativas del espectador y la interferencia de series (p. 69). Estos recursos en la obra de Castelnuovo se pueden percibir, en particular, en los comportamientos automáticos de sus personajes, que responden de manera irreflexiva a pautas y mandatos, en la parodización de los géneros literarios predominantes de su época -como la narrativa sentimental-y en sus desenlaces trágicos o desconcertantes que traicionan las expectativas de "finales felices". Asimismo, el humor de Castelnuovo se muestra como especialmente negativo, en correspondencia con las características de la "risa moderna" según Mijail Bajtín, que se distingue por colocarse fuera del objeto aludido y oponerse a él para buscar su destrucción (2003, p. 13). De esta manera, el humor de Castelnuovo se diferencia de la comicidad del sainete, por ejemplo, en tanto, como afirma Umberto Eco, lo cómico no implica el cuestionamiento radical de las reglas, sino solo su puesta en suspenso momentánea, mientras que el humorismo "representaría su crítica consciente y explícita" (1999, p. 284). Por su parte, el tono trágico de las ficciones de Castelnuovo se puede advertir en que sus argumentos responden a la concepción clásica de la tragedia, en tanto los protagonistas caen en la desdicha como consecuencia de algún tipo de conducta errónea y desmedida. No obstante, las tragedias de sus obras se ven atravesadas por constantes recursos humorísticos y, especialmente, por una estructuración paródica y satírica, que le confiere un singular tono tragicómico a su poética.

\section{Castelnuovo, autor teatral: Ánimas benditas (1926)}

Ánimas benditas es la primera obra de teatro de Elías Castelnuovo y fue estrenada en el Teatro Ideal, el 9 de abril de 1926, según consta en el libro homónimo publicado ese año. En este volumen está acompa- 
ñada de otras ficciones narrativas de Castelnuovo en Los Pensadores, que hasta el momento no habian aparecido en formato libro. A su vez, en 1926 Castelnuovo también publica el cuento "Ánimas benditas" en Entre los muertos, compilación de su autoría. Respecto de su argumento, la obra comparte por completo los personajes, ambientes, conflictos y desenlaces del cuento, con mínimas modificaciones que favorecen la representación dramática.

Ánimas benditas tiene por protagonista a Herminia, quien se encuentra convaleciente en un hospital a causa de una tuberculosis. El nombre de la protagonista establece un guiño cómplice y humorístico con una compañera de Boedo, Herminia Brumana, dado que el personaje invierte los rasgos de esta periodista y escritora de tendencia anarquista y cuyas publicaciones ficcionales y ensayisticas abogaban por la libertad y la igualdad para las mujeres. ${ }^{1}$ Por el contrario, el personaje Herminia es una mujer católica, cuya única aspiración consiste en curarse de su enfermedad para poder retornar a la vida familiar con su marido, con su pequeño hijo Cucho y con sus padres, ambos también católicos.

La obra se desarrolla durante el día de navidad y los padres de Herminia rezan para que pueda salir del hospital y pase la cena en familia. En la noche, se oyen carcajadas "roncas y macabras" (Castelnuovo, 1926, p. 44) que provienen de "una persona enloquecida que rie destempladamente" (pp. 43-44). Luego de dudarlo, la madre abre la puerta y surge Herminia que "rie con frenesí, enseñando la dentadura descarnada y lívida que le daba todo el aspecto de una calavera" (p. 44). Imágenes similares se encuentran en todas las obras de Castelnuovo y condensan las claves de su poética: en este caso, la risa de Herminia denota irónicamente la tragedia futura, en el mismo gesto en que se efectúa un distanciamiento sarcástico de la mentalidad católica y del amor familiar como realización de la felicidad. Michel Foucault, en este sentido, señala que uno de los rasgos fundamentales de la literatura moderna consiste en su capacidad de ofrecer su propia "autorreferencia" (1996, p. 88), es decir, una "implicación que la obra se hace a sí misma" (p. 89) como forma de dar indicios sobre sus estrategias de sentido.

En el desenlace, Herminia muere en la mesa como consecuencia de su tuberculosis, su débil y enfermizo hijo corre gran riesgo de haber sido contagiado por sus reiterados besos y tanto Pancho como sus suegros niegan la situación y creen que Herminia se encuentra dormida.

De esta manera, cualquier expectativa de felicidad se ve frustrada y la obra puede leerse como una crítica paródica de la narrativa sentimental de la época y, en particular de las obras de Hugo Wast, alias de

1. Este mismo recurso humorístico se repite en distintas partes de su obra respecto de Lelio Zeno, Guillermo Facio Hebequer, Juan Palazzo y, claro, con él mismo. 
Gustavo Martínez Zuviría, escritor nacionalista católico de gran alcance en la época. Como señala Bajtín, la parodia es un modo de imitación en la literatura de otro discurso del que toma distancia y sobre el que recae "el permanente correctivo de la risa y de la crítica" (1989, p. 424). En las novelas de Wast, la religión y el matrimonio funcionan como una garantía de felicidad para sus personajes, ya sea en la tierra o en el cielo, aunque estuvieran atravesando las peores calamidades. ${ }^{2}$ Por el contrario, como ocurría en los relatos anteriores de Castelnuovo, en Ánimas benditas el catolicismo y la institución familiar, lejos de brindar una posibilidad de felicidad y superación de las problemáticas que atraviesan los personajes, solo impiden comprender la situación real, acrecientan sus padecimientos y obturan cualquier alternativa superadora.

\section{Las obras de Castelnuovo en Teatro Libre y en Teatro Experimental del Arte (1927-1929)}

Respecto del contexto artístico y cultural de la época, la necesidad de una renovación teatral es una preocupación frecuente en las páginas de las revistas del Grupo de Boedo. En el primer número de Claridad, continuadora de Los Pensadores, de julio de 1926, aparece publicado el artículo "El teatro nacional en crisis", de Edmundo Caprara, que condensa la perspectiva que se adopta desde la revista sobre el tema en los siguientes números y que se muestra coherente con los posicionamientos previos de Castelnuovo. En este artículo, Caprara cuestiona el teatro comercial y señala que existe la necesidad de crear un "teatro de vanguardia", pese a las resistencias que pueda generar entre el público y la crítica. Pone como ejemplo de este tipo de teatro a Elías Castelnuovo, en relación, muy probablemente, con su obra Ánimas benditas, estrenada poco tiempo antes. Asimismo, en las notas editoriales del número 8 de Claridad, de 1927, se hace referencia a la necesidad de renovar no solo "la forma, sino también la estructura [del teatro]; hay que renovar todo: el traje, la escenografia, el maquillaje, las luces". ${ }^{3}$ En el número 12 , de abril de 1927, se publican las bases del "Teatro libre" y en esta "Declaración" se formula un diagnóstico y una propuesta muy similar a la que se proponía en los números previos de Claridad, revista que se constituye, según estas bases, en el "órgano oficial de la institución"

2. La narrativa sentimental, afirma Beatriz Sarlo, está constituida por textos en donde la felicidad se encuentra al "alcance de la mano [...], anclada en el [...] matrimonio y la familia" (2000, p. 22) y en la creencia de que "el mundo no debe necesariamente ser cambiado para que los hombres y las mujeres sean felices" (p. 22).

3. Para un análisis de la importancia del Teatro Libre en el desarrollo del concepto del "teatro independiente" en Argentina, ver Fukelman (2017). 
(Castelnuovo et al., 1927, s/n). La "Declaración" lleva la firma de Elías Castelnuovo, Leónidas Barletta, Guillermo Facio Hebequer, Octavio Palazzolo, Augusto Gandolfi Herrero, Abraham Vigo, Álvaro Yunque y H. Ugazio. Al año siguiente, en el número 164, de agosto de 1928, en la sección "Bibliográfica", se comunica que la experiencia de Teatro Libre se reformuló en el grupo Teatro Experimental de Arte. La primera obra de este grupo en estrenarse fue En nombre de Cristo, de Elías Castelnuovo, por parte de la compañia de Angelina Pagano.

Bajo ese marco, en 1929 se reedita Animas benditas junto con otros dos textos teatrales de Castelnuovo: En nombre de Cristo y Los señalados. Esta reedición tiene el plus de que cuenta con diez reproducciones de los bocetos escenográficos que Abraham Vigo hizo para las obras. Como señala Andrés Monteagudo, estas escenografias revelan "un amplio conocimiento de las novedades del teatro expresionista" (2012, p. 115), que se hace evidente si se las cotejan, por ejemplo, con la ambientación de la película El gabinete del Doctor Caligari (1920), de Robert Wiene, clásico del cine expresionista alemán. ${ }^{4}$

Los claroscuros, la arquitectura con líneas entrecortadas y arcos en punta, la simbología cristiana, el ambiente nocturno, entre otros rasgos, permiten advertir la estrecha semejanza entre ambas propuestas. Asimismo, estas vinculaciones entre las escenografias del teatro de Castelnuovo y el expresionismo alemán se muestran coherentes con la propuesta expresionista de su narrativa. En los relatos de Tinieblas (1923), por ejemplo, se ofrece una denuncia de las condiciones de trabajo en el capitalismo, en concordancia con el manifiesto expresionista de Herman Bahr, de 1916, en donde se cuestiona el hecho de que las personas se vean reducidas a ser "mero instrumento" (1988, p. 103) y a "servir a la máquina" (p. 103). La prosa de Castelnuovo, de frases breves y de aparente simplicidad, pero cargadas de referencias literarias e implícitos, muestra correspondencias, a su vez, con la caracterización que propone Lotte Eisner $(2014$, p. 16) del estilo narrativo expresionista al igual que, desde un aspecto visual, su gusto por los contrastes violentos, los claroscuros y las sombras (21). De manera convergente, César Aira advierte como rasgo expresionista en la obra de Roberto Arlt que su mundo literario "ha perdido su naturaleza cristalina, se hace gomoso, opaco, de barro" (1993, p. 55) así como José Amícola percibe en su narrativa "cierta conjunción inarmónica de colores, luces y movimientos" (2008, p. 161). Estas características pueden advertirse, también, en las obras que Castelnuovo publica antes que Arlt, de quien era su

4. La película The Cabinet Of Dr. Caligari, de Robert Wiene, se encuentra disponible en el siguiente enlace, con subtitulos en castellano: https://archive.org/details/NightOf TheLivingDeadwithSpanishSubtitles. 
amigo y referente literario, así como en su literatura posterior. Por su parte, Magalí Devés encuentra vinculaciones entre estas escenografias de Vigo y las vanguardias históricas, en particular con la "tendencia cubofuturista" (2020, p. 142), al igual que en los trajes y la iluminación, ambos a cargo de Facio Hebequer. La autora sostiene que estas búsquedas formales, que abrevan de la "síntesis y la abstracción" (p. 143),

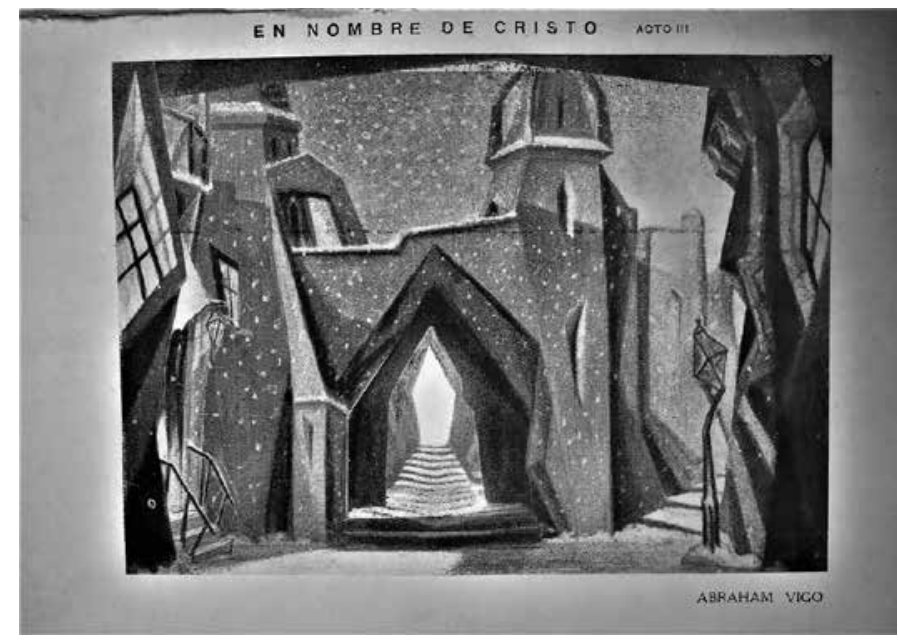

"En nombre de Cristo", Acto 3.

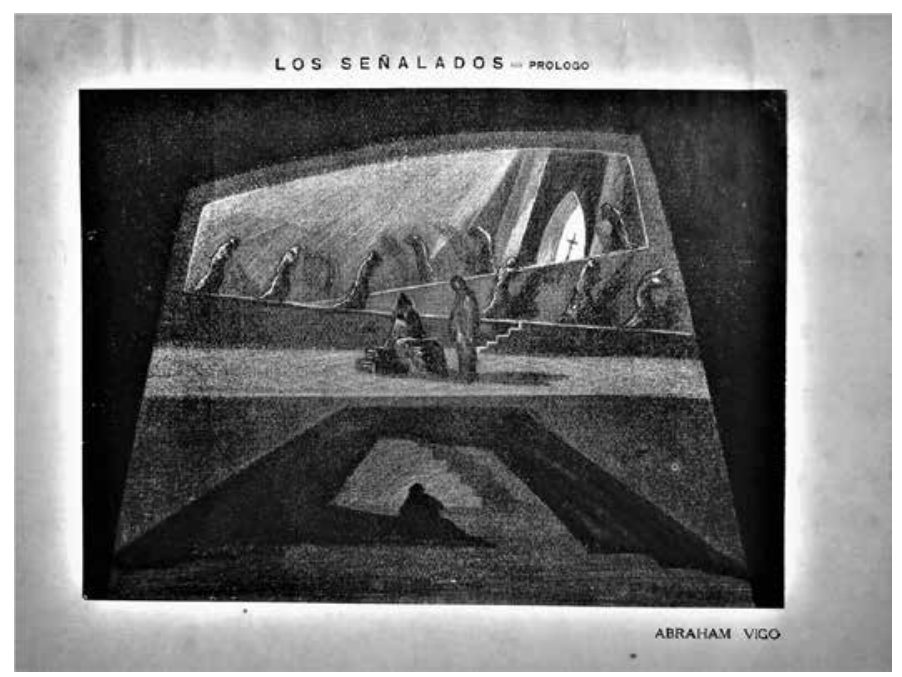

“Los señalados”, Prólogo. 


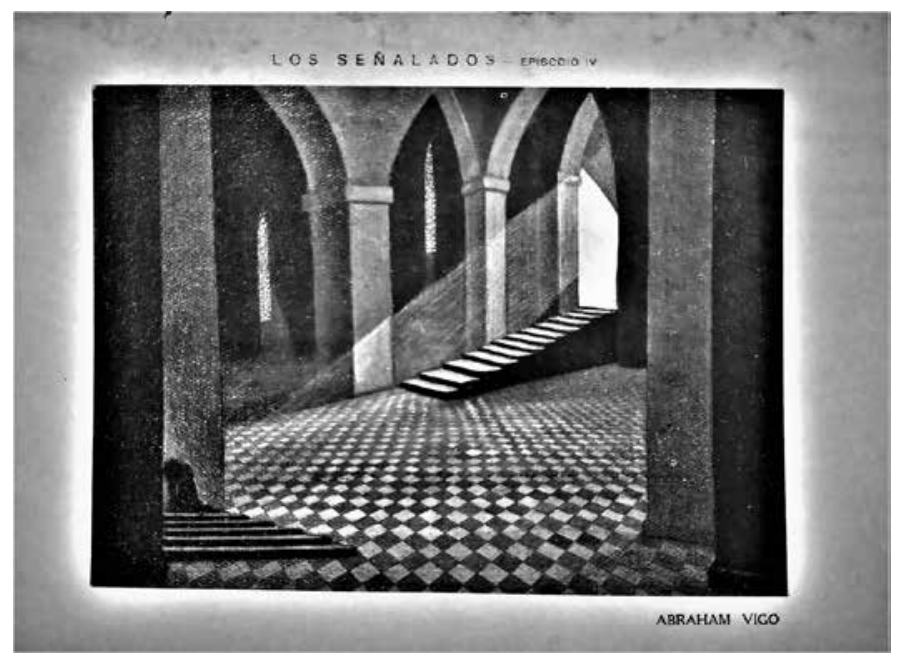

"Los señalados", Episodio IV

intentan diferenciarse del costumbrismo del sainete, predominante en las puestas en escena de la época.

Respecto de las obras En nombre de Cristo y Los señalados, sus argumentos establecen continuidades con el tono crítico de Ánimas benditas y de la narrativa de Castelnuovo. En ambas obras se cuestionan los valores cristianos bajo los que se enmarcan manifestaciones pacíficas en la Rusia zarista de comienzos del siglo XX. En particular, en estos textos dramáticos se parecen condensar dos acontecimientos históricos de relevancia: el Domingo Sangriento y la Primera Guerra Mundial (1914-1918). El Domingo Sangriento aconteció en San Petersburgo el 22 de enero de 1905, día en el que decenas de miles de trabajadores marcharon frente al Palacio de Invierno, residencia del zar Nicolás II, para reclamar por aumento salarial y mejoras en las condiciones de trabajo. Durante la manifestación se portaban imágenes cristianas y retratos del zar, con el fin de dejar en evidencia su carácter pacífico. La jornada finalizó con una cruenta represión por parte de los cosacos, en donde fueron asesinados al menos mil manifestantes y otros ochocientos quedaron heridos.

La obra teatral En nombre de Cristo, en efecto, se ubica en "las inmediaciones de una ciudad populosa, durante las alternativas de una conflagración universal" (Castelnuovo, 1929, p. 47) y entrama en paralelo dos historias vinculadas. Por un lado, relata la organización, por parte de una asamblea de mujeres, de una marcha en la que transportarían la figura de un Cristo para reclamarle al Emperador que termine la guerra 
y que les devuelvan a sus allegados. Por otro, cuenta la espera de una familia de la llegada de Lucas, uno de los hijos que se encontraba en el frente de batalla. En el final, los padres reciben consternados el cadáver de Lucas y la marcha de mujeres -pese a las imprecaciones a Dios- es ferozmente reprimida por cosacos que asesinan a muchas de ellas. El tono tragicómico de la obra lo aportan dos personajes, la Loca y Santiago. La Loca se encuentra afectada psíquicamente por la muerte de su hijo en la guerra e interrumpe repetidas veces la asamblea de mujeres con sus risas y comentarios que son recibidos negativamente, en los que dice, por ejemplo, que al emperador hay que cortarle la cabeza y que los hijos de las otras mujeres también ya están muertos. Por su parte, Santiago es un excombatiente que, como consecuencia del estallido de una granada, perdió un brazo y tuvo lesiones en la cabeza, motivo por el que es sordomudo y solo puede reír con "una risa desarticulada y estúpida" (p. 46) e imitar con su boca un "ruido semejante al tiro de un fusil" (p. 46). Si bien a lo largo de la trama son personajes secundarios que aportan pasajes sarcásticos de una ironía bufonesca, toman gran relevancia en el desenlace. La Loca es la primera en darse cuenta de que el Emperador no se hace eco de los reclamos y que envía a los cosacos para atacar la manifestación y, pese a que advierte a sus compañeras, no es escuchada. Santiago es el último que queda en escena, en soledad, con el Cristo de la procesión de fondo "sobre un tendal de sombras inmóviles" (p. 104). Ante ese panorama, exclama su característico “¡Bum... bum!" que, aunque con anterioridad provocaba risa, en este contexto multiplica el efecto trágico del final.

La obra Los señalados transcurre, al igual que En nombre de Cristo, en el contexto de una "guerra continental" (p. 107) y en la Rusia prerrevolucionaria, dado que, nuevamente, aparecen referencias al emperador y a los cosacos. Como consecuencia de las derrotas en el frente de batalla, el estado amplía la leva de soldados y comienza a convocar a hombres casados. Por este motivo, Samuel, uno de los protagonistas de la obra, debe dejar a su familia, y su hermano Marcos, religioso de clausura, más adelante también se sumará al ejército. Una caravana de ancianos mora en el convento y marcha por la ciudad, a la espera de la nueva llegada del Mesías, mientras que Marcos se siente el elegido para traer la paz entre los pueblos. En ese contexto, se destaca el personaje de la Mendiga quien, a semejanza de la Loca de En nombre de Cristo, se rie "de una manera forzada y perversa" (p. 135). La Mendiga duerme en la estación y exhibe en un cartel cuántas personas parten a la guerra y cuántas retornan, para demostrar lo cruento de la matanza. Samuel finalmente regresa a la ciudad pero está ciego por heridas de guerra. En el comienzo del último acto se ve en escena el cadáver estrangulado de su hermano Marcos, disfrazado burlescamente como Cristo, con un 
cartel colgado que dice "traidor a la patria" (p. 170). Del conjunto de su batallón, solo queda vivo el Capitán, que enloqueció luego de la explosión de una granada y alterna, en un nuevo gesto tragicómico, momentos de lucidez con otros en los que continúa participando de un combate imaginario. En la escena final, la madre le pregunta al cadáver de Marcos “¿qué has hecho, hijo mío?” (p. 174), y su corazón responde, en un giro fantástico, "quise hacer la paz" (p. 174). En la última escena de la obra, cargada de ironía, la caravana de ancianos religiosos continúa clamando por la nueva llegada del Mesias.

Como es una constante en Castelnuovo, estos finales trágicos defraudan toda expectativa de felicidad depositada en las súplicas a Dios o en arrebatos mesiánicos individuales, como el de Marcos. A su vez, el foco puesto por ambas obras en la situación de la Rusia zarista a comienzos del siglo XX manifiesta la continuidad del interés de Castelnuovo por la historia y la cultura de este país, como se advierte desde sus primeras publicaciones, y establece un paralelismo posible entre aspectos de la situación rusa previa al estallido revolucionario y el presente en el que se escriben y estrenan las obras en la Argentina. Asimismo, la aparición de personajes bufonescos en ambas obras evidencia un humor negativo y sarcástico como procedimientos fundamentales del tono crítico de su teatro.

\section{Los presupuestos teóricos de Elías Castelnuovo: la "Introducción" a Vidas proletarias (1934)}

En 1930, Castelnuovo retorna a la narrativa y publica la novela Carne de cañón, que consiste en la ampliación del cuento "Notas de un literato" (1923), y continúa realizando una crítica paródica y humorística del naturalismo literario, del discurso médico positivista, y del determinismo biológico. Al año siguiente, Castelnuovo, según cuenta en sus Memorias (1974, p. 148), visita la URSS como acompañante de su amigo Lelio Zeno, con quien había trabajado como asistente durante varios años. Castelnuovo había compartido con Zeno distintos medios periodísticos anarquistas durante las décadas anteriores y, a raíz de sus intereses políticos y su condición de médico, había sido invitado al Instituto Sklifosovsky, el establecimiento de cirugia de urgencia más grande de Moscú. En 1932, ya de regreso en Buenos Aires, Castelnuovo publica crónicas de su viaje a la URSS en el diario Bandera Roja y en la revista Actualidad (económica-politica-social), ambos medios vinculados con el PC, aún en su relativa autonomía. ${ }^{5}$ Por diferencias del consejo

5. Por ejemplo, unos de los grandes impulsores de esta revista en su fundación fueron los oposicionistas de izquierda Antonio Gallo y Héctor Raurich. 
editor de Actualidad con la perspectiva que Castelnuovo ofrece de la URSS -en especial, de la imagen que da de Stalin y de la "moral sexual" del proletariado soviético- Castelnuovo se aleja de la revista. En paralelo, Rodolfo Ghioldi, uno de los principales dirigentes del partido, entabla una polémica con Arlt en Bandera Roja, en torno de la importancia de la formación y de la función de los intelectuales dentro de la estructura política y, luego de finalizada, Arlt deja de participar en ese diario. Estas polémicas con intelectuales no afiliados y sus alejamientos de estas publicaciones se corresponden con el sectarismo del PC propio de la política del "tercer período", adoptada por la Internacional Comunista a partir de 1928, refractaria respecto de cualquier pensamiento de izquierda que se alejara de los lineamientos del PC. No obstante, un nuevo momento de las relaciones entre Castelnuovo y los medios cercanos al partido se define en 1934, cuando vuelve a formar parte de la redacción de Actualidad, que coincide con el cambio de política del PC y su llamado a la conformación de "frentes populares" antifascistas, de mayor amplitud ideológica.

En efecto, Castelnuovo, en sus textos ensayísticos y literarios posteriores a su reingreso a Actualidad en 1934, no muestra un cambio fundamental en su perspectiva ideológica y literaria. Ese mismo año, publica el libro Vidas proletarias, compilación de tres obras de teatro propias, la homónima Vidas proletarias y otras dos obras más breves, La marcha del hambre y La 77 conferencia de la paz mundial, producidas durante la experiencia del Teatro Proletario, iniciada en 1932. Asimismo, por primera vez incluye en sus libros una extensa "Introducción" de su autoria, en la que realiza una explicitación de su concepción de la literatura, implícita en su obra ficcional, que se muestra coherente con aquella presentada de manera asistemática en sus artículos periodísticos previos. ${ }^{6}$ En este sentido, en esa "Introducción" afirma que "la literatura proletaria se halla muy escasamente desarrollada en Argentina" (Castelnuovo, 1934, p. 5) como consecuencia de dos factores: por un lado, el "retraso" económico respecto de Europa y Rusia y, por otro, en función del sometimiento cultural imperialista realizado por Estados Unidos y Gran Bretaña. No obstante, reconoce que existió en el pasado un "sector revolucionario" (p. 6) en el arte local, que si bien en su forma era "un arte realista y pujante", su "fondo" era "resignado y místico" (pp. 7-8). En estas afirmaciones se pueden advertir, por ejemplo, críticas al realismo social de Manuel Gálvez, uno de los principales escritores de la generación anterior, cuando Castelnuovo concluye que

6. Castelnuovo publicará al año siguiente una ampliación de estas ideas en su ensayo El arte y las masas (1935). 
La pequeña burguesía, entonces, metida a redentora, en lugar de expresar las aspiraciones de la clase obrera, expresaba de contrabando sus propias aspiraciones, confundiendo, frecuentemente, el socialismo científico que tiene por sujeto al proletariado y por objeto la revolución social con el cretinismo parlamentario o con la filantropia de la iglesia. (Castelnuovo, 1934, p. 13)

En Nacha Regules (1919), novela de gran repercusión y que es publicada como folletín en La Vanguardia, órgano del Partido Socialista (PS), Manuel Gálvez relata las aspiraciones mesiánicas del pequeñoburgués Fernando Monsalvat, quien intenta lograr que una trabajadora sexual, de quien lleva su nombre la obra, deje su actividad. En este conflicto se perciben los principales elementos, no sin contradicciones, de la ideología nacionalista-católica de Manuel Gálvez y de su apuesta por un reformismo social, de raigambre en el PS, que impregna gran parte de su obra. Asimismo, puede advertirse de qué manera el relato "Tinieblas", de Castelnuovo, parodia el argumento de esta novela.

Ahora bien, Castelnuovo tampoco toma como modelo de la "literatura proletaria" en nuestro país a la literatura soviética que se produjo luego de la Revolución, por responder a distintos momentos históricos y coyunturas culturales. Por el contrario, entiende que la literatura proletaria rusa se manifiesta "inversamente a cómo debe manifestarse la nuestra" (Castelnuovo, 1934, p. 19) y en esta "inversión" se cifra, precisamente, uno de los núcleos fundamentales de la poética de Castelnuovo:

La literatura proletaria rusa es una literatura constructiva, en virtud de que atraviesa la etapa de la construcción del socialismo. La nuestra, en cambio, es o debe ser destructiva, en razón de que cruza la recta de la destrucción del capital. Toda la literatura rusa, ahora, está absorbida por un solo pensamiento: construcción. La nuestra no puede ser absorbida más que por la idea contraria: destrucción. (Ídem, p. 19)

De esta manera, entonces, la apuesta de Castelnuovo por un humor tragicómico desde sus primeros escritos se muestra como su forma de destruir las expresiones culturales dominantes, que favorecian la reproducción ideológica del capitalismo dentro de su contexto histórico.

\section{El teatro de Vidas proletarias (1934): críticas humorísticas a la política capitalista y a las organizaciones revolucionarias}

Las obras teatrales incluidas en Vidas proletarias (1934) mantienen 
el tono tragicómico, aún en sus diversas modulaciones, como manifestaciones de la poética de la destrucción de Castelnuovo. Al mismo tiempo, presentan un cambio respecto de sus producciones previas: algunas de sus obras también ponen el foco, de manera crítica, en la organización política de los trabajadores, en particular, en las tensiones entre el movimiento anarquista, el sindicalismo y el PC. Este cambio puede deberse al reflujo del movimiento anarquista en la década del 30 y al crecimiento concomitante de la importancia de la organización sindical institucionalizada y del PCA en la clase trabajadora. Dentro de ese marco, la obra Vidas proletarias se estructura a partir de cuatro "Episodios" y un "Epílogo" que relatan distintas "escenas de la lucha obrera", como dice su subtítulo. La primera de estas escenas, "La huelga", cuenta cómo un grupo de obreros "de filiación anárquica, [...] se ha reunido [...] al margen de la asamblea, a fin de estudiar la liquidación física de los crumiros" (Castelnuovo, 1934, p. 28). Entre estos trabajadores se encuentra El Negro, "obrero de la juventud comunista" (p. 28), quien intenta persuadir a sus compañeros de la necesidad de "conquistar" a los rompehuelgas para conformar un "frente único", en lugar de perseguirlos violentamente. No obstante, sus intervenciones no tienen éxito dado que, como le responde Romo, allí pertenecen "todos a la FORA" (p. 32). Por su parte, el "Epílogo" de la obra transcurre en una cárcel, en la que se encuentran encerrados distintos personajes por motivos políticos, que habian aparecido por separado en las sucesivas escenas. El Director del presidio, el Centinela y el Guardia, en el momento en que están organizando su traslado a Ushuaia, advierten que las mujeres de los detenidos organizaron una marcha hacia el penal para reclamar por la liberación de sus familiares presos. Mientras el Director pide que "disuelvan inmediatamente" (p. 36) la manifestación con represión, los presos, quienes se encuentran ya sobre el camión de traslado, comienzan a cantar "La Internacional" junto con las manifestantes. El Director observa la situación y expresa "todavía mandamos nosotros" (p. 36) y la obra concluye con el Centinela y otras voces lejanas que gritan, sugerentemente, "iAlertaaaaa!", poniendo en entredicho, como efecto de lectura, el alcance de la afirmación anterior de su superior y ofreciendo un final en donde la tensión dramática continúa abierta.

Mientras Vidas proletarias hace foco en la lucha de trabajadores ocupados, la segunda obra, La Marcha del Hambre tiene como protagonistas a desocupados que, asimismo, se organizan politicamente. Respecto de la participación en estos conflictos de "jóvenes comunistas", en "La Marcha del Hambre" se expresan con mayor relieve los límites que sus formas de intervención pueden tener desde la perspectiva autoral. Así, un desocupado ironiza sobre estos personajes cuando exclama que los activistas del PC hacen sus propuestas porque "idespués los palos no los 
reciben ellos!" (p. 96). Si bien se pondera la voluntad de los militantes comunistas en la obra, su accionar se muestra externalista y forzado e implica que ellos parecen concebir que sus compañeros deben responder linealmente a sus consignas.

Por otro lado, junto con los cuestionamientos al capitalismo en la voz de los personajes y en la descripción de sus extremas condiciones de vida, una vez más el sarcasmo se dirige hacia la Iglesia a través de una de las protagonistas de la obra, quien, al ver la comida que reparten unos curas a los desocupados, señala entre burlas e ironías que es una "bazofia" (p. 119) hecha con un revoltijo de sus sobras. Este tipo de intervenciones de El Lechuzón actualizan el tono tragicómico de sus ficciones anteriores, asi como también la figura del Obrero gigantesco, que participa en reiteradas ocasiones para expresar un mismo lamento -repetitivo y automático- que genera una risa amarga, dada la inutilidad de sus enormes músculos al encontrarse sin trabajo. Asimismo, las intervenciones del Alemán, también desocupado, se construyen a partir de la exageración humorística y crítica de la postura de Karl Kautsky en el contexto de la Segunda Internacional. En el último episodio, luego de una elipsis en donde se presupone que se inició la marcha de protesta de los desocupados y que, como consecuencia de una represión, ahora se encuentran realizando una barricada, se relata que, nuevamente, las fuerzas avanzan sobre los manifestantes. Una vez más, el final es abierto $\mathrm{y}$, de esta manera, en los desenlaces de las dos obras se encuentran rasgos coincidentes con aquellos de su producción anterior: lejos de presentar finales felices y de idealizar a sus personajes y a los resultados de su accionar, se suspenden los acontecimientos en un momento de tensión, en el que los protagonistas no lograron sus objetivos y se encuentran presos o asediados, es decir, en peores condiciones que en la situación dramática inicial. No obstante, en estas obras teatrales la organización política de los personajes y la resistencia a la opresión se muestran como la posibilidad de provocar un cambio.

Por último, La 77 Conferencia de la Paz Mundial, tercera obra de la compilación, tiene un abierto tono satírico para la crítica de la hipocresía de las principales potencias mundiales luego de la Primera Guerra Mundial. Así, en la didascalia inicial, se señala que en el fondo del escenario "se alza un Cristo crucificado, resguardado por una careta contra los gases asfixiantes" (p. 131) y se describe que "el respaldo de los asientos [de los congresales] se parece extraordinariamente al cilindro de un cañón" (p. 131). Con el escenario vacío, aparece la cabeza de un personaje que dice "iComincha la farsa!" y refuerza el sentido humorístico de la obra. La Conferencia se inicia con una discusión entre los delegados de Alemania y Francia respecto de con cuál de los dos himnos de sus respectivos países es más adecuado dar comienzo a la 
sesión, conflicto que es zanjado por el Presidente quien propone, en su reemplazo, realizar "iun minuto de silencio en homenaje a la paz!" (p. 133). Este tipo de giros sarcásticos y disparatados son una constante a lo largo de la obra. La "farsa" alcanza su punto máximo de intensidad cuando, sobre el final, el Presidente resuelve tratar el último punto de la reunión, el "desarme", pero los distintos delegados, pese al nombre de la Conferencia, se niegan. Luego, el Presidente pregunta quién fue el que presentó el proyecto sobre este punto que se encuentra sobre la mesa y responde afirmativamente el Delegado Soviético, que hasta ese momento no había hablado. Este delegado lee su proyecto, recibe insultos de los otros presentes y su propuesta es rechazada. Cuando se retira, se dirige al Cristo que colgaba sobre el fondo y lo interpela preguntándole “¿Y, tú, qué has hecho por la paz del mundo?”, y recibe de respuesta: "¿Y qué quiere que haga, amigo, por tres pesos por día? ¿No ve que a mí me han contratado para hacer de Cristo?” (p. 157). A continuación de esta humorada, aparece nuevamente el personaje que habia intervenido en el comienzo, quien exclama "iLa comedia e finita!" (p. 157) y, una vez más, se ofrece un final que deja inconclusa la principal tensión dramática. Este procedimiento, recurrente en Castelnuovo, puede funcionar como un indice de que, desde la perspectiva entramada en las obras, las principales problemáticas que atraviesa el proletariado aún se encuentran abiertas y que su resolución depende, en gran medida, del propio accionar de la clase trabajadora.

\section{Conclusiones}

La obra dramática de Castelnuovo que se produce entre 1926 y 1934 tuvo un papel preponderante en la renovación teatral y muestra, como constante, un humor tragicómico para la crítica de los discursos, las ideologias y la sociedad dominantes. Asimismo, las distintas obras evidencian una transformación de los objetos de sus críticas en relación con los cambios de la dinámica social y de las preocupaciones de los sectores revolucionarios de la clase trabajadora. De esta manera, sus primeras obras -Ánimas benditas (1926), En nombre de Cristo (1928) y Los señalados (1929)- se caracterizan, al igual que su obra narrativa anterior, por la crítica a la pregnancia del catolicismo en el proletariado y a su confianza en Dios y en la institución familiar como formas de resolver sus problemáticas. Esta selección del objeto a destruir se encuentra en correlación con la importancia de la Iglesia Católica entre amplios sectores de la clase y, en particular, con el éxito de la narrativa sentimental durante esos años. Si en otras experiencias vanguardistas de la época, como en la revista Martín Fierro y el grupo de Florida, el humor hacía foco principalmente en ridiculizar la poética y la figura 
de otros escritores, con el fin de abrirse un espacio dentro del campo literario, en la obra de Castelnuovo el humor se politiza: las parodias, sátiras e ironías buscan horadar no solo las formas literarias, sino también sus presupuestos ideológicos. En este sentido, su teatro se propone configurar una alternativa a las propuestas comerciales y oficiales y su primera obra dramática es tomada como referente para el grupo Teatro Libre (1927) así como, luego, sus producciones son las primeras en ser estrenadas bajo el marco del Teatro Experimental del Arte (1928). Castelnuovo, en efecto, no se limita a generar una alternativa al teatro predominante desde su contenido, sino también desde la búsqueda de formas artísticas vanguardistas y experimentales. De esta manera, apuesta por producir sus obras en el marco de proyectos colectivos, apropiándose de elementos de las vanguardias históricas y con una orientación política consciente que, no obstante, no se circunscribe a preceptivas ajenas a los propios colectivos creadores.

Desde lo temático, lejos de idealizar al proletariado o tener una actitud "pietista", Castelnuovo ofrece en sus obras una perspectiva crítica sobre su mentalidad y sus prácticas, al tiempo que muestra a la organización política como la alternativa para transformar el estado de cosas existente. No obstante, su teatro no se convierte en un instrumento para la difusión de consignas partidarias, sino que se constituye como una instancia para el cuestionamiento de las propias organizaciones de los trabajadores. Esto ocurre, en particular, respecto del PCA en sus textos de Vidas proletarias (1934), de un modo análogo al que lo había hecho años antes en sus crónicas de viaje a la URSS. De esta manera, se puede advertir que en su apoyo crítico al PCA se encuentra implícito el anarcobolchevismo de Castelnuovo, que se mantiene, aún en sus inflexiones, como un sustrato ideológico permanente a lo largo de su obra. Así, su propuesta se distancia de toda mirada simplificadora y, por el contrario, pone en evidencia los límites de perspectivas dogmáticas tanto en el arte como en la politica. Es decir, si en sus ficciones aparecen personajes con una mentalidad exageradamente esquemática, esto ocurre con el fin de criticar, valiéndose del humor tragicómico, precisamente a este tipo de formas de abordar la realidad social.

La imbricación entre la risa tragicómica, la denuncia social y elementos vanguardistas manifiesta la singularidad y originalidad de la poética de la destrucción de Castelnuovo y, en el mismo gesto, pone en evidencia su rechazo a la imitación de modelos literarios previos o al acatamiento de preceptivas ordenadas desde centros políticos. La consideración de estas características permite releer el conjunto de su obra desde una perspectiva alternativa a la mayoritaria y advertir la coherencia entre su literatura y los proyectos político-culturales de los que participó. Asimismo, abre la posibilidad de elaborar nuevas hipótesis para el abordaje 
de la producción literaria de las autoras, autores y revistas culturales del campo de la izquierda de la época.

\section{Bibliografía}

Aira, C. (1993), Arlt. Paradoxa, 7, pp. 55-71.

Amícola, J. (2008), Fritz Lang, Alfred Döblin y Roberto Arlt. En W. Nitsch, M. Chihaia y A. Torres (eds.), Ficciones de los medios en la periferia. Técnicas de comunicación en la literatura hispanoamericana moderna, Universitäts und Stadtbibliothek Köln, pp. 161-169.

Astutti, A. (2002). Elias Castelnuovo o las intenciones didácticas de la narrativa de Boedo. En M.T. Gramuglio (dir.). El imperio realista. Emecé, pp. 417-446.

Bahr, H. (1988). Expresionismo. Artes Gráficas Soler.

Bajtín, M. (1989). Teoría y estética de la novela. Taurus.

Bajtín, M. (2003). La cultura popular en la Edad Media y en el Renacimiento. El contexto de François Rabelais. Alianza.

Bergson, H. (2009). La risa. Ensayo sobre el significado de lo cómico. Losada. Blanco, O. (2012). Modulaciones de un realismo (/naturalismo) militante. Direcciones invertidas: del naturalismo argentino a la literatura de Boedo. En M. Vitagliano (comp.), Boedo. Politicas del realismo (pp. 15-52). Editorial Título.

Candiano, L. y Peralta L. (2007). Boedo: Origenes de una literatura militante. Historia del primer movimiento cultural de izquierda argentina. Ediciones del CCC.

Caprara, E. (1926). El teatro nacional en crisis. Claridad, 1.

Castelnuovo, E. (1919a). Críticas teatrales: El sainete, Prometeo, 4, pp. 13-14.

Castelnuovo, E. (1919b). Literatura proletaria, Prometeo, 5, pp. 11-12.

Castelnuovo, E. (1923). Notas de un literato naturalista. Las Grandes Obras.

Castelnuovo, E. (1926). Ánimas benditas. Atlas.

Castelnuovo, E. (1929). Teatro: Ánimas benditas, En nombre de Cristo, Los señalados. El Inca.

Castelnuovo, E. (1934). Vidas proletarias. Victoria.

Castelnuovo, E. (1974). Memorias. Ediciones Culturales Argentinas.

Castelnuovo E. (2020). Elias Castelnuovo: "Prefiero Estar Equivocado con las Masas". TestimoniosBA. https://www.testimoniosba.com/2020/09/03/ elias-castelnuovo-prefiero-estar-equivocado-con-las-masas /.

Castelnuovo E., L. Barletta, G. Facio Hebequer y otros (1927). Bases del Teatro Libre, Claridad, 12.

Croce, M. (2017). Novelistas y cronistas de la monstruosidad: avatares del grotesco en el primer cuarto del siglo XX. En M. Croce (comp.), Historia comparada de las literaturas argentina y brasileña: de la crisis bursátil al nacionalismo católico: 1890-1922, pp. 184-240. Eduvim.

Devés, M. (2020). Guillermo Facio Hebequer. Entre el campo artístico y la cultura de izquierdas. Prometeo. 
Doeswijk, A. (2013). Los anarco-bolcheviques rioplatenses (1917-1930). CeDInCI.

Ducrot, O. y Todorov, T. (2005). Diccionario enciclopédico de las ciencias del lenguaje. Siglo XXI.

Eco, U. (1999), La estrategia de la ilusión. Lumen.

Eipper, J.E. (1995). Elias Castelnuovo. La revolución hecha palabra. Rescate.

Eisner, L. (2014). La pantalla diabólica. Cuenco de Plata.

Foucault, M. (1996). De lenguaje y literatura. Paidós.

Fukelman, M. (2017). Los inicios del teatro independiente en Buenos Aires y su vínculo con la macropolítica. Anagnórisis, 16, pp. 105-129. http:// www.anagnorisis.es/pdfs /n16/MariaFukelman(105-129)n16.pdf

García Cedro, G. (2013). Ajuste de cuentas. Boedo y Florida entre la vanguardia y el mercado. Santiago Arcos.

Giordano, C. (1980). Boedo y el tema social [1968]. En S. Zanetti (ed.), Los proyectos de la vanguardia, pp. 25-48. CEAL.

Hutcheon, L. (1992), Ironía, sátira, parodia. Una aproximación pragmática a la ironía. En H. Silva, De la ironía a lo grotesco (en algunos textos literarios hispanoamericanos), Universidad Autónoma Metropolitana, pp. 171-193.

Masiello, F. (1986). Lenguaje e ideologia: las escuelas argentinas de vanguardia. Hachette.

Monteagudo, A. (2012). El teatro de las tinieblas. En M. Vitagliano (comp.), Boedo. Politicas del realismo, pp. 117-132.

Portantiero, J.C. (1961). Realismo y realidad en la narrativa argentina. Procyón.

Prieto, A. (1959). La literatura de izquierda. El grupo de Boedo. Fichero, 2, pp. 17-20.

Rodríguez Pérsico, A. (2013). Capitalismo y exclusión. Elías Castelnuovo y la búsqueda de una lengua heterogénea, Estudio preliminar de E. Castelnuovo, Larvas, pp. 9-84. Biblioteca Nacional.

Romano, E. (1981). El cuento. 1900-1930. En S. Zanetti (ed.), Las primeras décadas del siglo, pp. 457-480. CEAL.

Rosa, N. (1997). La lengua del ausente. Biblos.

Saitta, S. (2008). Elías Castelnuovo, entre el espanto y la ternura. En Á.F. Bolaños, G. Cleary Nichols y S. Sosnowski (eds.), Literatura, politica y sociedad: construcciones de sentido en la Hispanoamérica contemporánea. Homenaje a Andrés Avellaneda, pp. 99-113. Universidad de Pittsburg.

Sarlo, B. (1988). Una modernidad periférica: Buenos Aires 1920-1930. Nueva Visión.

Sarlo, B. (2000). El imperio de los sentimientos. Narraciones de circulación periódica en la Argentina (1917-1927) [1985]. Norma.

Suriano, J. (2001). Anarquistas: cultura y politica libertaria en Buenos Aires, 1890-1910. Manantial. 